\title{
Erratum: Kirk, Langan-Evans, \& Morton (2020)
}

In the article Kirk, C., Langan-Evans, C., \& Morton, J. P. (2020). Worth the weight? Post weigh-in rapid weight gain is not related to winning or losing in professional mixed martial arts, International Journal of Sport Nutrition and Exercise Metabolism,
30(5), 357-361, https://doi.org/10.1123/ijsnem.2019-0347, the abstract listed the wrong number of bout winners and losers. There were 62 bout winners and 62 bout losers, not 31 bout winners and 31 bout losers. The online version of this article has been corrected. 